\title{
HEALTH SEEKING BEHAVIOR AMONG RICKSHAW PULLERS IN DELHI AND THEIR ACCEPTANCE OF USING MOBILE PHONETO SEEK HEALTH INFORMATION
}

\author{
Shikha Gill, Anandhi Ramachandran \\ International Institute of Health Management Research Delhi, India
}

\begin{abstract}
Background: Rickshaw pullers of India are one among the vulnerable population in India and have no or limited access to health service and have poor health condition. Most of them are migrants and have shifted to urban cities like Delhi and Agra to earn a livelihood to support their families left behind. Low socioeconomic status, unhygienic living environment, and improper diet, lead to their health problems. As they are unable to visit their families frequently they keep in touch with them through mobile phones. Although health information seeking of the consumers through the mobile has received great attention, limited attempt has been made to understand the same in context of vulnerable population. The aim of this study is to explore the health seeking behavior of rickshaw pullers in Delhi and their acceptance towards the use of mobile phones to seek health related information
\end{abstract}

Subjects and Method: This was a qualitative study with case studies approach conducted at two metro stations and market place where there were significant available numbers of rickshaw pullers. A sample of 75 rickshaw pullers was selected by simple random sampling. The data were collected by survey of rickshaw pullers based on semi-structured questionnaires.

Results: This study found out that more than $90 \%$ of the rickshaw pullers were migrants from North Indian states and $70 \%$ had migrated more than five years ago. Regarding their health seeking behavior most of them used home based cures or consulted pharmacies and local doctors. Many were unaware of the government health facilities and the services available to them. Their intention to seek health information through mobiles and use the information was influenced by the information quality, perceived value, ease of use, method and cost of receiving information and trust on the source.

Conclusion: The current study throws light on the factors affecting the mobile based health information seeking behavior of the rickshaw pullers and provides valuable insights that can be used for developing mobile health interventions for the vulnerable population.

Keywords: health information, mobile phones, rickshaw pullers, health seeking behavior

\section{Correspondence:}

Shikha Gill. International Institute of Health Management Research Delhi, Dwarka Sector 18 A, New Delhi 110075, India.

Email: shikhaparttapgill@gmail.com. 